\title{
Organic molecular anions in interstellar and circumstellar environments
}

\author{
M. A. Cordiner ${ }^{1}$, T. J. Millar ${ }^{1}$, C. Walsh ${ }^{1}$, E. Herbst ${ }^{2}$, D. C. Lis ${ }^{3}$, \\ T. A. Bell ${ }^{3}$, and E. Roueff ${ }^{4}$ \\ ${ }^{1}$ Astrophysics Research Centre, School of Mathematics and Physics, Queen's University, \\ Belfast, BT7 1NN, U.K. \\ email: m.cordiner@qub.ac.uk \\ ${ }^{2}$ Departments of Physics, Astronomy and Chemistry, The Ohio State University, Columbus, \\ OH 43210, U.S.A. \\ email: herbst@mps . ohio-state.edu \\ ${ }^{3}$ California Institute of Technology, MC 320-47, Pasadena, CA 91125, U.S.A. \\ email: dcl@caltech.edu \\ ${ }^{4}$ LUTh \& UMR 8102 du CNRS, Observatoire de Paris, 5, Place J. Janssen, F-92190, \\ Meudon, France \\ email: Evelyne.Roueff@obspm.fr
}

\begin{abstract}
The synthesis of organic molecular anions in TMC-1 and IRC +10216 is investigated. Modelled $\mathrm{C}_{2} \mathrm{H}^{-}, \mathrm{CN}^{-}, \mathrm{C}_{3} \mathrm{~N}^{-}, \mathrm{C}_{5} \mathrm{~N}^{-}$and $\mathrm{C}_{7} \mathrm{~N}^{-}$column densities are sufficiently great that these species might be observable in IRC +10216 . Density-enhanced shells in the outer envelope of IRC+10216 are found to enhance the $\mathrm{C}_{2} \mathrm{H}^{-}$and $\mathrm{CN}^{-}$column densities by shielding these anions from destruction by UV radiation. From a newly-derived upper column density limit of $6.6 \times 10^{10} \mathrm{~cm}^{-2}$ for $\mathrm{C}_{2} \mathrm{H}^{-}$in IRC+10216 we deduce the primary production mechanism for this anion to be $\mathrm{C}_{2} \mathrm{H}_{2}+\mathrm{H}^{-} \longrightarrow \mathrm{C}_{2} \mathrm{H}^{-}+\mathrm{H}_{2}$. In TMC-1, due to the low radiative electron attachment rates calculated for $\mathrm{C}_{2} \mathrm{H}^{-}, \mathrm{CN}^{-}$and $\mathrm{CH}_{2} \mathrm{CN}^{-}$, these species have modelled column densities below the detection threshold. They could, however, be produced in reactions we have not yet considered.
\end{abstract}

Keywords. Astrochemistry, ISM: molecules, ISM: abundances, ISM: clouds, stars: carbon

\section{Introduction}

The molecular anions $\mathrm{C}_{4} \mathrm{H}^{-}, \mathrm{C}_{6} \mathrm{H}^{-}$and $\mathrm{C}_{8} \mathrm{H}^{-}$have recently been detected in large quantities in the envelope of the carbon-rich AGB star IRC+10216 (McCarthy et al. 2006, Cernicharo et al. 2007, Remijan et al. 2007). $\mathrm{C}_{6} \mathrm{H}^{-}$and $\mathrm{C}_{8} \mathrm{H}^{-}$have also been detected in the cold, dense interstellar cloud TMC-1 (McCarthy et al. 2006, Brüenken et al. 2007), and $\mathrm{C}_{4} \mathrm{H}^{-}$and $\mathrm{C}_{6} \mathrm{H}^{-}$in the protostellar source L1527 (Sakai et al. 2007, Agúndez et al. 2008). Fractional abundance ratios of the anions relative to their neutral parents of up to 0.1 indicate that anions may play a more significant role in interstellar physics and chemistry than previously believed.

The possibility that a relatively large fraction of interstellar molecular material might be in the form of anions was first suggested by Herbst (1981) who pointed out that carbon chain molecules and other radicals with large electron affinities may have high radiative attachment rates, leading to interstellar anion-to-neutral ratios of the order of a few percent. Using detailed chemical models (Millar et al. 2007) we have previously considered the formation of hydrocarbon anions in IRC+10216 and TMC-1 and were able to reproduce the large observed anion abundances. In these proceedings, results 
Table 1. Calculated anion and neutral molecular column densities $\left(N / \mathrm{cm}^{-2}\right)$ from chemical models of TMC-1 and IRC+10216. Anion-to-neutral ratios $R=N\left(\mathrm{X}^{-}\right) / N(\mathrm{X})$ are also given.

\begin{tabular}{|c|c|c|c|c|}
\hline \multirow[b]{2}{*}{ Species } & \multicolumn{2}{|c|}{ TMC-1 } & \multicolumn{2}{|c|}{ IRC +10216} \\
\hline & $N$ & $R$ & $N$ & $R$ \\
\hline $\mathrm{C}_{2} \mathrm{H}^{-}$ & $1.4 \times 10^{9}$ & & $6.1 \times 10^{10}$ & \\
\hline $\mathrm{C}_{2} \mathrm{H}$ & $4.9 \times 10^{13}$ & $2.9 \times 10^{-0}$ & $5.2 \times 10^{15}$ & $1.2 \times 10^{-6}$ \\
\hline $\mathrm{C}_{3} \mathrm{H}^{-}$ & $3.0 \times 10^{10}$ & & $2.7 \times 10^{6}$ & \\
\hline $\mathrm{C}_{3} \mathrm{H}$ & $1.8 \times 10^{13}$ & 0.0021 & $1.4 \times 10^{14}$ & $1.9 \times 10^{-8}$ \\
\hline $\mathrm{C}_{4} \mathrm{H}^{-}$ & $8.1 \times 10^{10}$ & & $2.4 \times 10^{13}$ & \\
\hline $\mathrm{C}_{4} \mathrm{H}$ & $1.1 \times 10^{13}$ & 0.0077 & $1.6 \times 10^{15}$ & 0.015 \\
\hline $\mathrm{C}_{5} \mathrm{H}^{-}$ & $1.9 \times 10^{11}$ & & $1.5 \times 10^{13}$ & \\
\hline $\mathrm{C}_{5} \mathrm{H}$ & $4.1 \times 10^{12}$ & 0.045 & $2.3 \times 10^{14}$ & 0.065 \\
\hline $\mathrm{C}_{6} \mathrm{H}^{-}$ & $1.9 \times 10^{11}$ & & $9.0 \times 10^{13}$ & \\
\hline $\mathrm{C}_{6} \mathrm{H}$ & $3.2 \times 10^{12}$ & 0.059 & $1.3 \times 10^{15}$ & 0.069 \\
\hline $\mathrm{C}_{7} \mathrm{H}^{-}$ & $3.7 \times 10^{11}$ & & $5.6 \times 10^{13}$ & \\
\hline $\mathrm{C}_{7} \mathrm{H}$ & $1.9 \times 10^{12}$ & 0.19 & $4.1 \times 10^{14}$ & 0.14 \\
\hline $\mathrm{C}_{8} \mathrm{H}^{-}$ & $2.6 \times 10^{11}$ & 0,047 & $2.0 \times 10^{13}$ & 0045 \\
\hline $\mathrm{C}_{8} \mathrm{H}$ & $5.4 \times 10^{12}$ & 0.047 & $4.4 \times 10^{14}$ & 0.045 \\
\hline $\mathrm{C}_{9} \mathrm{H}^{-}$ & $4.5 \times 10^{11}$ & & $1.8 \times 10^{13}$ & \\
\hline $\mathrm{C}_{9} \mathrm{H}$ & $3.2 \times 10^{12}$ & 0.14 & $1.6 \times 10^{14}$ & 0.11 \\
\hline $\mathrm{C}_{10} \mathrm{H}^{-}$ & $1.0 \times 10^{11}$ & & $5.6 \times 10^{12}$ & \\
\hline $\mathrm{C}_{10} \mathrm{H}$ & $2.5 \times 10^{12}$ & 0.041 & $1.6 \times 10^{14}$ & 0.0035 \\
\hline $\mathrm{CN}^{-}$ & $3.3 \times 10^{5}$ & & $1.4 \times 10^{10}$ & \\
\hline $\mathrm{CN}$ & $1.1 \times 10^{13}$ & $2.9 \times 10^{-8}$ & $2.4 \times 10^{15}$ & $5.8 \times 10^{-6}$ \\
\hline $\mathrm{C}_{3} \mathrm{~N}^{-}$ & $5.5 \times 10^{8}$ & & $8.5 \times 10^{9}$ & \\
\hline $\mathrm{C}_{3} \mathrm{~N}$ & $7.9 \times 10^{11}$ & $7.0 \times 10^{-4}$ & $4.1 \times 10^{13}$ & $2.1 \times 10^{-4}$ \\
\hline $\mathrm{C}_{5} \mathrm{~N}^{-}$ & $3.4 \times 10^{9}$ & & $1.3 \times 10^{13}$ & \\
\hline $\mathrm{C}_{5} \mathrm{~N}$ & $6.5 \times 10^{10}$ & 0.053 & $2.2 \times 10^{14}$ & 0.059 \\
\hline $\mathrm{C}_{7} \mathrm{~N}^{-}$ & $3.4 \times 10^{9}$ & & $2.9 \times 10^{12}$ & 0.051 \\
\hline $\mathrm{C}_{7} \mathrm{~N}$ & $6.5 \times 10^{10}$ & 0.053 & $5.7 \times 10^{13}$ & 0.051 \\
\hline $\mathrm{CH}_{2} \mathrm{CN}^{-}$ & $7.0 \times 10^{7}$ & $2, \times 10^{-5}$ & $7.2 \times 10^{6}$ & $10^{-7}$ \\
\hline $\mathrm{CH}_{2} \mathrm{CN}$ & $2.7 \times 10^{12}$ & $2.6 \times 10$ & $2.4 \times 10^{13}$ & $3.0 \times 10$ \\
\hline
\end{tabular}

are presented from updated models of these environments, which include the additional anions $\mathrm{C}_{2} \mathrm{H}^{-}, \mathrm{C}_{3} \mathrm{H}^{-}, \mathrm{CN}^{-}, \mathrm{C}_{3} \mathrm{~N}^{-}, \mathrm{C}_{5} \mathrm{~N}^{-}, \mathrm{C}_{7} \mathrm{~N}^{-}$and $\mathrm{CH}_{2} \mathrm{CN}^{-}$.

\section{TMC-1}

We modelled the chemistry of TMC-1 using the time-dependent model described by Woodall et al. (2007), augmented with the $\mathrm{C}_{n} \mathrm{H}^{-}$anion chemistry from Millar et al. (2007) extended down to $n=2$. Electron radiative attachment rates for $\mathrm{C}_{n} \mathrm{H}$ species are from Herbst \& Osamura (2008). Chemical networks for $\mathrm{C}_{2 n+1} \mathrm{~N}^{-}$species are from the model by Millar et al. (2000), with an additional $\mathrm{C}_{3} \mathrm{~N}^{-}$formation channel involving dissociative electron attachment to $\mathrm{HNC}_{3}$ (the chemistry for which has been taken from the OSU database (Harada \& Herbst 2008). $\mathrm{CH}_{2} \mathrm{CN}^{-}$is assumed to be formed by radiative electron attachment to $\mathrm{CH}_{2} \mathrm{CN}$, the rate for which was calculated using the phase-space approach discussed by Herbst \& Osamura (2008). The electron affinity of $\mathrm{CH}_{2} \mathrm{CN}$ was taken to be $1.55 \mathrm{eV}$ (Lykke et al. 1987), and the necessary vibrational frequencies were estimated to be the same as those of the isoelectronic $\mathrm{NH}_{2} \mathrm{CN}$. The $G$ value, expressing the ratio of the electronic degeneracy of the anion to that of the reactants was set to $1 / 4$. The rate coefficient $k_{r}$ for radiative stabilization of the anion was estimated to be $500 \mathrm{~s}^{-1}$ based on calculated values of analogous ions, while the rate coefficient $k_{-1}$ for dissociation of the anionic complex was calculated to be $1.79 \times 10^{8} \mathrm{~s}^{-1}$. Since $k_{-1}$ is much greater than $k_{r}$, radiative attachment to $\mathrm{CH}_{2} \mathrm{CN}$ is relatively inefficient.

Anions in the TMC-1 model are destroyed predominantly in reactions with atomic $\mathrm{H}$, $\mathrm{C}, \mathrm{N}$ and $\mathrm{O}$. Results are shown in Table 1. 


\section{IRC +10216}

We have updated the chemical model of IRC+10216 (Millar et al. 2000, Millar et al. 2007) to be consistent with the chemical reaction rates in the (dipole-enhanced) RATE06 database (Woodall et al. 2007). Initial $\mathrm{C}_{2} \mathrm{H}_{2}$ and $\mathrm{HCN}$ abundances are from Fonfria et al. (2008). Anion chemistry has been updated to include the additional species mentioned in Section 2. Further, the following $\mathrm{CN}^{-}$and $\mathrm{C}_{2} \mathrm{H}^{-}$formation reactions have been included (with rate coefficients from Prasad \& Huntress 1980, Mackay et al. 1977):

$$
\begin{gathered}
\mathrm{HCN}+\mathrm{H}^{-} \longrightarrow \mathrm{CN}^{-}+\mathrm{H}_{2} \\
\mathrm{C}_{2} \mathrm{H}_{2}+\mathrm{H}^{-} \longrightarrow \mathrm{C}_{2} \mathrm{H}^{-}+\mathrm{H}_{2}
\end{gathered}
$$

These processes are important in IRC+10216 (and not in TMC-1) due to the large abundances of $\mathrm{HCN}$ and $\mathrm{C}_{2} \mathrm{H}_{2}$ in the stellar outflow. $\dagger$ Dominant anion destruction mechanisms are by reaction with $\mathrm{H}$ and photodetachment by the interstellar radiation field. Photodetachment rates were calculated according to Eq. 2 of Millar et al. (2007). $\ddagger$ The model (which will be explained in detail by Cordiner \& Millar 2008), includes density-enhanced shells of gas and dust which have been observed in the stellar outflow (Mauron \& Huggins 2000, Dinh-V-Trung \& Lim 2008). Seven concentric shells are included; each is $2^{\prime \prime}$ thick with a gas and dust density 5 times greater than the underlying density distribution and an inter-shell spacing of $8^{\prime \prime}$. The presence of shells increases the shielding of the inner envelope from interstellar UV radiation, which allows $\mathrm{CN}^{-}$and $\mathrm{C}_{2} \mathrm{H}^{-}$to survive photodetachment for longer and raises their column densities (by about a factor of two) compared to models without shells.

Results of the IRC+10216 model are shown in Table 1. Notable new species included in this model that have sufficiently high column densities to be detectable with current instruments include $\mathrm{C}_{2 n-1} \mathrm{~N}^{-}$(for $n=1$ to 4 ). $\mathrm{C}_{2} \mathrm{H}^{-}$is predicted to be detectable, and during the preparation of this article new data were recorded at the Caltech Submillimeter Observatory which place a $3 \sigma$ upper limit of $6.6 \times 10^{10} \mathrm{~cm}^{-2}$ on the column density of $\mathrm{C}_{2} \mathrm{H}^{-}$in IRC +10216 . This value was obtained from a preliminary analysis of a $J=3-2$ spectrum, using an estimated Einstein $A$ coefficient of $7.44 \times 10^{-4} \mathrm{~s}^{-1}$ and an assumed (LTE) rotational temperature of $20 \mathrm{~K}$ for the molecule. This upper limit is consistent with our modelled column density of $6.1 \times 10^{10} \mathrm{~cm}^{-2}$.

To produce $\mathrm{C}_{2} \mathrm{H}^{-}$, we have also considered reactions of the kind (Mackay et al. 1977)

$$
\mathrm{C}_{2} \mathrm{H}_{2}+\mathrm{X}^{-} \longrightarrow \mathrm{C}_{2} \mathrm{H}^{-}+\mathrm{XH}
$$

for the various anions $\mathrm{X}^{-}$in our model. However, such reactions cannot be rapid (with the exception of Eq. (3.2), i.e. $\mathrm{X}=\mathrm{H}$ ), because they would result in a modelled $\mathrm{C}_{2} \mathrm{H}^{-}$column density $\sim 100$ times greater than the observed upper limit. It is therefore hypothesised that reaction 3.3 is endothermic for anions $\mathrm{X}^{-}$with high electron binding energies such as $\mathrm{C}_{n} \mathrm{H}^{-}$and $\mathrm{C}_{n}^{-}$.

\section{4. $\mathrm{CH}_{2} \mathrm{CN}^{-}$and dipole-bound electronic states}

$\mathrm{CH}_{2} \mathrm{CN}^{-}$has been included in these models due to the suggestion by Cordiner \& Sarre (2007) that this molecule could be the carrier of the $8037 \AA$ diffuse interstellar band. In both TMC-1 and IRC +10216 the modelled $\mathrm{CH}_{2} \mathrm{CN}^{-}$abundance is very low due to the small rate of anion formation by radiative electron attachment. Unless an alternative, more rapid, production mechanism exists for this anion, its low calculated

$\dagger \mathrm{H}^{-}$is produced in the model mainly by cosmic-ray dissociation: $\mathrm{H}_{2}+\mathrm{CR} \longrightarrow \mathrm{H}^{+}+\mathrm{H}^{-}$.

$\ddagger$ The $\mathrm{CN}^{-}$photodetachment rate used here is $\sim 100$ times less than the value in the RATE06 database. 
abundances suggest that the oscillator strength of the responsible transition must be exceptionally high for $\mathrm{CH}_{2} \mathrm{CN}^{-}$to be the carrier of any DIBs. It has been suggested (see, e.g., Sommerfeld 2005, Cordiner \& Sarre 2007) that dipole-bound electronic states (possessed by strongly dipolar molecules) may assist in the formation of some anions by acting as a doorway through which rapid radiative stabilisation can occur. This effect might increase the abundance of potential DIB-carrying anions such as $\mathrm{CH}_{2} \mathrm{CN}^{-}$in the diffuse ISM, and may also be important in radiative electron attachment to $\mathrm{C}_{n} \mathrm{H}$ species with dipole moments $\gtrsim 2.5 \mathrm{D}$ (i.e., $n \neq 1,2,4$ ), perhaps reconciling some of the discrepancies (see Agúndez et al. 2008) between current observational and theoretical anion-to-neutral ratios.

\section{Summary}

Our new chemical models calculate abundances of $\mathrm{CN}^{-}, \mathrm{C}_{2} \mathrm{H}^{-}$and $\mathrm{C}_{3} \mathrm{~N}^{-}$that suggest these species may be observable in IRC+10216 but not in TMC-1. $\mathrm{C}_{5} \mathrm{~N}^{-}$and $\mathrm{C}_{7} \mathrm{~N}^{-}$might be observable in both sources due to their high calculated anion-to-neutral ratios of $\sim 5 \%$. There is some uncertainty in these predictions due to the uncertain nature of the adopted rate coefficients. Further experimental and theoretical work is needed to constrain these rate coefficients, together with further observational studies of anions in a variety of extraterrestrial regions.

\section{References}

Agúndez, M., Cernicharo, J., Guélin, M. et al. 2008, A\&A, 478, 19

Brünken, S., Gupta, H., Gottlieb, C. A. et al. 2007, ApJ (Letters), 664, L43

Cernicharo, J., Guélin, M., Agündez, M. et al. 2007, A\& A (Letters), 467, L37

Cordiner, M. A. \& Millar, T. J. 2008, in preparation

Cordiner, M. A. \& Sarre, P. J. 2007, A\&A, 472, 537

Dinh-V-Trung \& Lim, J. 2008, ApJ, in press

Fonfria, J. P., Cernicharo, J., Richter, M. J., \& Lacy, J. H. 2008, ApJ, 673, 445

Harada, N. \& Herbst, E. 2008, in preparation

Herbst, E. 1981, Nature, 289, 656

Herbst, E. \& Osamura, Y. 2008, ApJ, in press

Lykke, K. R., Neumark, D. M., Andersen, T., Trapa, V J., \& Lineberger, W. C. 1987, J. Chem. Phys., 87, 12, 6842

Mauron, N. \& Huggins, P. J. 2000, A\&3A, 359, 707

Mackay, G. I., Tanaka, K., \& Bohme, D. K. 1977, Int. J. Mass Spec., 24, 125

McCarthy, M. C., Gottlieb, C. A., Gupta, H. C., \& Thaddeus, P. 2006, ApJ (Letters), 652, L141

Millar, T. J., Herbst, E., \& Bettens, R. P. A. 2000, MNRAS, 316, 195

Millar, T. J., Walsh, C., Cordiner, M. A., Ní Chuimín, R., \& Herbst, E. 2007, ApJ (Letters), $662, \mathrm{~L} 87$

Prasad, S. S. \& Huntress Jr., W. T. 1980, ApJSS, 43, 1

Remijan, Anthony J., Hollis, J. M., Lovas, F. J., Cordiner, M. A., Millar, T. J., MarkwickKemper, A. J., \& Jewell, P. R. 2007, ApJ (Letters), 664, L47

Sakai, N., Sakai, T., Osamura, Y., \& Yamamoto, S. 2007, ApJ (Letters), 667, L65

Sommerfeld, T. 2005, J. Phys.:Conf.Ser, 4, 245

Woodall, J., Agúndez, M., Markwick-Kemper, A. J., \& Millar, T. J. 2007, A\&\&A, 466, 1197

\section{Discussion}

ZIURYs: You said that having anions helps you create cations as well. No one has really seen many cations in IRC +10216 . There was a tentative detection of $\mathrm{HCO}^{+}$and that was it. Did you actually predict the abundance of the cations like $\mathrm{HCO}^{+}$from your model of IRC $+10216 ?$

CoRDINER: Yes. Incorporating anions does give us a better fit between the model and the observations for $\mathrm{HCO}^{+}$by reducing its abundance. 